\title{
PHAC to publicly disclose conflicts of interest of external advisors serving on advisory committees
}

$\mathrm{F}$ ew commodities hold more value in the field of public health than trustworthy advice. Ideally, expert advisors on decisions that affect the health of many people would be free of conflicts of interest, though they seem to be in short supply. Conflicts that do exist must be managed, according to experts on such matters, and at bare minimum be disclosed to the public.

In the United States, the Food and Drug Administration (FDA), which annually approves 25-30 new chemical entities, requires members of its advisory committees to sign public disclosures of conflicts of interest. The Public Health Agency of Canada (PHAC), however, does not yet require external experts serving on advisory committees to publicly disclose their financial ties to industry.

"It is completely 180 degrees opposed to the general public health principle we call the precautionary principle," says Dr. Sidney Wolfe, director of the health research group at Public Citizen, a Washington, DC-based consumer rights advocacy group. "It is reckless and flies in the face of other important public health considerations."

PHAC Media Relations Advisor Charlene Wiles writes in an email that the agency requires external experts to privately disclose "real, potential or perceived situations of conflict of interest, prior to providing service, and during their term of service," and that it is currently developing a policy for public disclosure of information about advisory committee members.

Wiles also mentions that external advisors, selected for their expertise and experience, provide guidance but do not make decisions. "While the advisory committee provide advice and recommendations, the final decisions rests with the Agency and/or the appropriate provincial/territorial jurisdictions."

Still, the recommendations of expert

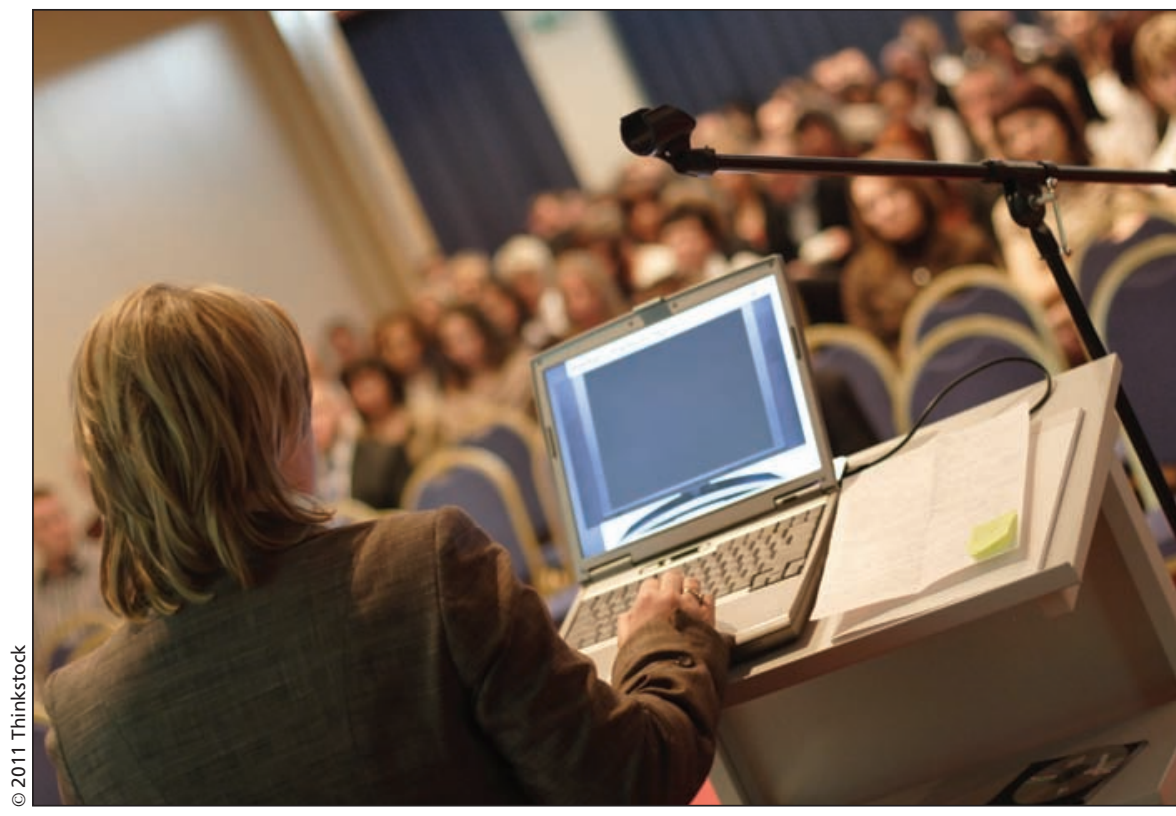

Medical experts paid by companies to deliver lectures on drugs or medical devices should publicly disclose their financial ties to industry when serving on advisory panels for public health agencies, say consumer rights advocates.

advisors carry weight, as suggested by the safeguards in place to reduce bias in FDA advisory committee meetings. Conflicts of interest are announced at each meeting and conflicted members are either excluded or, if the value of their input is considered greater than the magnitude of their conflicts, granted waivers.

The FDA also prohibits physicians or scientists (and, by extension, their immediate families and employers) who have more than US\$50 000 in financial ties to a company over the previous 12 months from participating on a panel reviewing one of that company's products. Medical experts who received less than US\$50 000 in the previous year can participate in a discussion but are not allowed to vote (www.cmaj.ca /lookup/doi/10.1503/cmaj.070548).

According to Wolfe, who sits on the FDA's drug safety and risk management advisory committee, people are excluded more often as a result of the strengthened FDA conflict-of-interest policy. But historically, conflicts have abounded among agency advisors, he says. "Why, in the past, did the FDA allow so many people with conflicts of interest to be involved in these meetings? The answer is, and this is probably the same in Canada, that they don't want to expend the energy to find people without conflicts of interest. It is much easier to find someone with a conflict of interest than without."

But the FDA has struggled to fill positions on some advisory committees, and excluding all candidates with financial ties to drug companies would no doubt make that problem worse. Still, it is possible to reduce the number of conflicts, as Wolfe and several colleagues noted in a 2006 study of 16 drug advisory committees (JAMA 2006;295:1921-8). "It is noteworthy that 7 of 16 advisory committees were able to keep their conflict rates at or below 20\%, suggesting that, with assiduous effort, advisory committees largely (or even completely) free of conflict of interest can be assembled," the paper states. 
Overall, though, there was at least one conflict of interest declared in $73 \%$ of the 221 meetings considered in the study. These conflicts took the form of investments in drug companies, consultant fees, research grants or honoraria for lectures, and sometimes exceeded US\$10 000 in value. In meetings about specific products, the conflict rate was $81 \%$, dropping to $66 \%$ for more general topics. And though conflicts were always declared, only $1 \%$ of advisory committee members were recused from participation.

If advisors do have a conflict of interest, does that necessarily mean their advice is biased? That is difficult, if not impossible, to prove. A common line of defence among advisors with industry ties is that they base their recommendations on data, not income. But Wolfe, for one, doesn't buy it. Just because someone isn't aware of their bias, he suggests, doesn't mean it isn't there.

"It is contrary to all of human history, to common sense and to logic that money doesn't influence you," he says. "These people are protecting themselves psychologically. They are unable to think that they could damage public health because of their financial stake in a decision. It is hard to overstate the power of denial. When there is a conflict between your conscience and your income, the income usually wins."

But setting monetary thresholds and demanding transparency aren't enough, says Dr. Martin McKneally, professor emeritus of surgery at the University of Toronto in Ontario and member of the Joint Centre of Bioethics. "Disclosure is not management," he says. "A threshold doesn't really solve the problem. It just sets a trigger."

Dealing with conflicts of interest in medicine and medical research isn't straightforward, says McKneally, who suggested in a 2007 paper that opinions differ on the effects of closer ties between industry and medical researchers (J Thorac Cardiovasc Surg 2007;133:300-2). "Some view this as a vicious cycle of increasing compromise of scientific integrity," the paper states. "Others see a virtuous cycle in which industrial partners provide the capacity for production, evaluation, and distribu- tion of new technology that could not be achieved without their help."

In the paper, McKneally lays out a three-part method for managing conflicts of interest: disclosure, mediation and prohibition. Disclosure is the first step, providing a "sunshine effect" that brings conflicts to light. Still, he notes, some disclosures are so vague — "has a financial relationship," for example - that the public remains in the dark about the magnitude and impact of potential biases. Mediation by an independent third party is a more "publicly defensible" means of handling conflicts. And prohibition may be necessary when the potential for harmful bias is too high to accept.

"It's an iterative and evolving process," says McKneally. "It's a little bit undermanaged at the moment, but it would be very prudent for anybody doing advisory committee work to be above the current standards in terms of public disclosures and to have a code of conduct for members." - Roger Collier, CMAJ

CMAJ 2011. DOI:10.1503/cmaj.109-3923 